\title{
Cerebrospinal Fluid Homovanillic Acid Predicts Behavioral Response to Stimulants in 45 Boys with Attention Deficit/Hyperactivity Disorder
}

F. Xavier Castellanos, M. D., Josephine Elia, M.D., Markus J. P. Kruesi, M.D., Wendy L. Marsh, B.A., Charles S. Gulotta, B.A., William Z. Potter, M.D., Gail F. Ritchie, M.S.W., Susan D. Hamburger, M.A., M.S., and Judith L. Rapoport, M.D.

Central dopaminergic activity has been assumed to play a role in the efficacy of stimulant drugs in attention deficit/ hyperactivity disorder ( $A D H D)$, although supporting evidence has been scant. This study examined baseline cerebrospinal fluid (CSF) of boys with ADHD in relation to response to three different stimulant drugs. Forty five boys with DSM-III-R-diagnosed ADHD had a lumbar puncture before double-blind trials of methylphenidate, dextroamphetamine, and placebo. Sixteen also received pemoline as part of a subsequent open trial. Stepwise linear regressions determined significant predictors of drug response. Our prior repori of a positive significant correlation between CSF homovanillic acid (HVA) and ratings of hyperactivity on placebo was replicated in a new sample of 20 boys. After baseline symptom severity, CSF HVA was the best predictor of stimulant drug response, with significant independent contribution to four of the ten measures of hyperactivity that changed significantly with medication. Higher HVA predicted better drug response, and lower HVA was associated with worsening on some measures. This supports the mediating role of central dopaminergic activity in stimulant drug efficacy in childhood hyperactivity. [Neuropsychopharmacology 14:125-137, 1996]
KEY WORDS: Attention deficit disorder with hyperactivity; Cerebrospinal fluid; Homovanillic acid; Analeptics; Psychostimulants; Drug effects

From the Child Psychiatry Branch (FXL, JLR, WLM, SDH, GFR), and Section on Clinical Pharmacology, Experimental Therapeutics Branch (WZP), Division of Intramural Research Program, National Institute of Mental Health, Bethesda, Maryland; Department of Psychiatry (JE), Medical College of Pennsylvania, Philadelphia; Institute for Juvenile Research (MJPK), University of Illinois at Chicago; Department of Psychology (CSG), Virginia Polytechnic Institute, Blacksburg, Virginia.

Address correspondence to: F. Xavier Castellanos, M.D., Child Psychiatry Branch, National Institute of Mental Health, Building 10, Room 6N240, Bethesda, MD 20892-1600.

Received August 31, 1994; revised April 17, 1995; accepted May 1, 1995.
The robust and immediate normalizing effects of the psychostimulants dextroamphetamine (DEX) and methylphenidate (MPH) on attention deficit/hyperactivity disorder (ADHD)-associated behaviors have focused interest on catecholaminergic circuits since 1970, when a functional deficit in central dopaminergic circuits was first hypothesized for ADHD (Kornetsky 1970; Wender 1973; Shaywitz et al. 1978; Gualtieri and Hicks 1985; Levy 1991; McCracken 1991). Due to the difficulty of conducting studies of cerebrospinal fluid (CSF) in psychiatrically ill children (Arnold et al. 1995), this hypothesis has been directly examined only rarely (Shaywitz et al. 1977). In fact, only one pediatric CSF study compared CSF monoamine metabolites before and after stimulant drug treatment (Shetty and Chase 1976), finding that the extent of decrease in CSF homovanillic acid 
(HVA) correlated highly with improvement on dextroamphetamine. However, the number of subjects was small $(n=10)$, fluorometric analyses were used, and other possible covariates such as baseline symptom severity were not reported. To date, no replications of this study have been carried out. Instead urinary and plasma monoamine metabolite concentrations have been examined with no peripheral measures consistently related to symptomatic severity or medication effects in ADHD (Zametkin et al. 1985a; Donnelly et al. 1986; Shekim et al. 1987; Zametkin and Hamburger 1988; Donnelly et al. 1989).

As part of an investigation into monoaminergic correlates of ADHD, drug-free baseline measures of monoamine metabolites were analyzed in CSF, plasma, and 24-hour urine collections. Although the peripheral measures again did not relate consistently to medication response (Elia et al. 1990), there was a positive significant correlation between CSF HVA concentration at baseline and ratings of severity of hyperactivity (Castellanos et al. 1994). We now present a replication with an independent sample of 20 additional subjects and examine the relationship of CSF monoamine metabolite levels to stimulant medication response obtained during a double-blind, cross-over, placebo-controlled trial of methylphenidate, and dextroamphetamine for the total sample of $45 \mathrm{ADHD}$ boys.

\section{SUBJECTS AND METHODS}

\section{Subjects}

Males, aged 6 to 12 years, with longstanding hyperactive, inattentive, and impulsive behaviors, were referred from area schools and health-care providers. Subjects met DSM-III-R criteria for ADHD in at least two settings (home, school, or day hospital) and had Conners hyperactivity factor scores from their home teacher and a parent at least $2 \mathrm{SD}$ greater than the age mean (Goyette et al. 1978; Werry et al. 1975). The majority $(80 \%)$ had been previously treated with stimulants. Exclusion criteria included a full scale IQ $<80$ on the Weschler Intelligence Scale for Children-Revised (WISC-R) (Wechsler 1974), evidence of medical or neurologic diseases, including Tourette's disorder, or any other Axis I psychiatric disorder, except conduct or oppositional disorder, mild overanxious disorder, and specific developmental disorders as determined from separate interviews of the child and a parent on the Diagnostic Instrument for Children and Adolescents (DICA)(Herjanic and Campbell 1977).

Fifty-four children were enrolled in the study. Two refused lumbar puncture after prior assent, CSF was unobtainable from four, one was excluded because of a comorbid diagnosis of Tourette's disorder, and samples from two subjects whose CSF had been previously analyzed could not be located for reanalysis. Thus, the study group consisted of 45 boys with a mean age of 8.7 years ( $\pm 1.7 \mathrm{SD}$, range 6 to 12 ) and a mean full scale IQ of 109.1 ( \pm 18.2 ) (range 83 to 148). In addition to ADHD, nine of the subjects also met DSM-III-R criteria for conduct disorder (all mild per DSM-III-R criteria), 15 for oppositional disorder, six had specific developmental disorders, nine were enuretic, one encopretic, and two had overanxious disorder, judged mild in relation to their ADHD.

\section{Methods}

All 45 subjects participated in a 9-week, double-blind, placebo-controlled, cross-over trial of methylphenidate (MPH) and dextroamphetamine (DEX) described in detail elsewhere (Borcherding et al. 1989; Elia et al. 1990; Elia et al. 1991). Briefly, subjects were randomly assigned to a cross-over trial of three weeks each of methylphenidate, dextroamphetamine, or placebo. Doses were given twice daily and increased weekly. The average MPH doses and their ranges were $13.0 \mathrm{mg}$ b.i.d. (12.5 to 15), $21.7 \mathrm{mg}$ (15 to 25 ), and $38.0 \mathrm{mg}$ (20 to 45 ) for weeks 1 to 3 , respectively. Average DEX doses for the three weeks were $6.2 \mathrm{mg}$ ( 5 to 7.5 ), $13.0 \mathrm{mg}$ (7.5 to 15), and $20.2 \mathrm{mg}$ (15 to 22.5 ). A subset of 16 subjects also participated in a trial of magnesium pemoline (PEM). Because of uncontrolled order effects (14 subjects participated in the pemoline trial after completing the MPH/ DEX trial), and the small numbers of patients enrolled, the data from a double-blind PEM/placebo trial $(n=10)$ have been combined with data from an open trial $(n=6)$ of PEM offered to subjects who had been initially assigned to double-blind placebo. Subjects received PEM once each morning for 28 days at a dose of $2 \mathrm{mg} / \mathrm{kg}$ for the first 4 days, $2.5 \mathrm{mg} / \mathrm{kg}$ for 6 days, and $3 \mathrm{mg} / \mathrm{kg}$ (to a maximum of $150 \mathrm{mg} /$ day) for days 11 to 28 (mean final dose $98.1 \mathrm{mg} /$ day).

Before the medication trials, subjects underwent a baseline evaluation of one to two weeks, which included physical and neurologic examinations, clinical and structured psychiatric interviews with the parent and child versions of the Diagnostic Instrument for Children and Adolescents (DICA-P and DICA-C), laboratory tests (CBC, SMAC, thyroid panel, blood lead), a psychoeducational assessment (WISC-R and Woodcock Johnson Achievement Battery [Woodcock and Johnson 1977]), behavioral ratings by the parents (Child Behavior Checklist) (Achenbach and Edelbrock 1983), and a lumbar puncture. During baseline and throughout the study, the Continuous Performance Test (CPT) (Rosvold et al. 1956) and the following weekly behavioral ratings were obtained: (1) the Conners 39-item Teacher Rating Scale (Goyette et al. 1978) completed by the ward teach- 
ers, (2) the Conners 48-item Parent Rating Scale (Werry et al. 1975), completed by the parents to evaluate their child's behavior at home, (3) the Children's Global Assessment Scale (C-GAS) (Shaffer et al. 1983) completed by a child and adolescent psychiatrist (JE or FXC). Side-effects were monitored weekly by the Subject Treatment Emergent Symptom Scale (STESS) (Guy 1976).

\section{Procedure}

The study was approved by the NIMH Institutional Review Board and explained in detail at an initial screening conference in which parents' written consent and subjects' assent were obtained. The consent and assent process continued during the baseline period in that in nearly all cases subjects were able to learn about the procedure from peers who had recently undergone it, and parents were able to discuss their concerns with other parents as well as with the treatment team. We also instituted a "dress rehearsal" on the day prior to the lumbar puncture (LP), which facilitated subject cooperation. Parents had the option of being present for the LP, which was performed during the second baseline week. Prior to the LP, all patients were medication free for a minimum of 4 weeks, and were on a low monoamine diet for at least 3 days. All were admitted as inpatients the night before the procedure to ensure bed-rest from midnight on, with one opportunity to void.

Lumbar puncture was performed in the lateral decubitus position between 8:30 A.M. and 9:30 A.M. A pediatric length 22-gauge spinal needle ( 2.5 inches) was inserted preferentially into the L4-L5 interspace to a depth estimated on the basis of the child's height, weight, and body surface area (Bonadio et al. 1988). Total CSF collected was $8 \mathrm{ml}$, with the first $3 \mathrm{ml}$ sent for standard clinical studies. The next $5 \mathrm{ml}$ were gently mixed, placed on ice, subdivided into tubes for storage, and stored at $-70^{\circ} \mathrm{C}$ until assayed by mass spectroscopy for levels of HVA, the dopamine metabolite, MHPG, the primary metabolite of norepinephrine, and 5-HIAA, the serotonin metabolite (Karoum 1983).

Details concerning subjective and objective responses to the LP are reported elsewhere (Castellanos et al. 1994). The procedure was tolerated well by the children, as confirmed immediately after the procedure and by follow-up interview with the children several months later (Kruesi et al. 1988a).

\section{STATISTICAL ANALYSIS}

Monoamine metabolite data were analyzed for statistical outliers ( $>3$ SD beyond mean). Measurement reli- ability was assessed by intraclass correlation (ICC) for 25 samples from the same pooled aliquots, which had been previously analyzed by high pressure liquid chromatography with electrochemical detection (Castellanos et al. 1994).

Analysis of variance (ANOVA) with medication phase (MPH, DEX, placebo) and week (1 to 3) as repeated measures was used to determine which measures changed significantly with medication for further correlational analysis.

Response to MPH or DEX treatment was then calculated as the difference between the average of each subject's 3 weekly ratings during the placebo phase and ratings for the best week during the medication phases (Rapport et al. 1986). "Best week" was defined for all measures as the week for each phase in which the subject received the lowest hyperactivity score (the average of six items, each scored 0 to 3 ) on the Conners Teacher Rating Scale. If the same rating was obtained at 2 different weeks (and therefore two different doses), the week on the lower dose was used.

For analysis of pemoline response, "best week" pemoline behavioral ratings were compared to the placebo phase scores from the MPH/DEX trial.

All analyses were performed using SAS version 6 (SAS Institute 1989). As the distribution of most variables was normal, Pearson correlations were obtained between CSF metabolites, age and height, because of their known relation to CSF values (Nordin et al. 1982; Kruesi et al. 1988b; Blennow et al. 1993; Shaywitz et al. 1980; Anderson et al. 1988; Hedner et al. 1986), and behavioral scores on double-blind placebo. CPT error data deviated substantially from the normal distribution using the method of Shapiro and Wilk (cited in SAS Institute 1990), therefore nonparametric Spearman correlations were used. Cerebrospinal fluid monoamine metabolites, age, height, and baseline behavioral ratings were entered into stepwise multiple regressions with behavioral change scores (placebo average minus "best week") as the outcome measure.

\section{RESULTS}

\section{Stimulant Response}

As expected, all stimulants were effective compared to placebo, and all were well tolerated. For the doubleblind, methylphenidate/dextroamphetamine/placebo comparison, repeated factor ANOVAs revealed significant effects of drug for teachers' and parents' factor IV (hyperactivity) ratings $\left(F_{(2,88)}=106.9\right.$, and $F_{(2,74)}=33.5$, respectively, $p<.0001)$, teacher and parent ratings of factor I (conduct) $\left(F_{(2,88)}=42.1, p<.0001\right.$; and $F_{(2,74)}=$ $9.9, p<.0002$, respectively) and for physicians' GAS 
score $\left(F_{(2,88)}=57.4, p<.0001\right)$. Methylphenidate also significantly decreased CPT omission (paired $t_{(41)}=$ 5.04, $p<.0001$, all tests two-tailed) and commission errors $\left(t_{(41)}=2.51, p<.02\right)$. Dextroamphetamine had comparable results for omission $\left(t_{(42)}=5.08 p<.0001\right)$ and commission errors $\left(t_{(42)}=3.02, p<.004\right)$.

Pemoline was also significantly more effective than placebo on teachers' and parents' ratings of hyperactivity (paired $t_{(15)}=4.17, p<.001$, and $t_{(14)}=3.65, p<.01$, respectively) and on the parent's ratings of conduct $\left(t_{(14)}=2.40, p<.05\right)$. There were significantly fewer CPT omission errors on pemoline $\left(t_{(14)}=3.11, p<.01\right)$, but the difference in commission errors did not attain significance $(p=.20)$. Physicians' GAS scores were significantly improved on pemoline compared to placebo $\left(t_{(14)}=4.56, p<.001\right)$; however, pemoline was clinically preferred for only one of the 16 subjects who tried all three stimulants.

\section{Cerebrospinal Fluid Monoamine Metabolite Levels}

Due to technical problems in the MHPG assay, there were six outliers in MHPG values, and none in HVA or 5-HIAA levels. These outlier MHPG values were deleted from further analysis. Intraclass correlation coefficients (ICC) for 25 samples previously analyzed by HPLC for HVA and 5-HIAA were 0.96 and 0.94 , respectively, $(p<.0001)$. ICC for 21 samples (excluding four outliers) for MHPG was only $0.44(p<.02)$. Mean metabolite concentrations for HVA, 5-HIAA, and MHPG were $366.4 \pm 93.8,111.3 \pm 26.8$, and $52.2 \pm 15.4$ $\mathrm{pmol} / \mathrm{ml}$, respectively. Though precise comparisons are not possible due to differences in methodology, subjects, and ages, our monoamine metabolite concentrations are consistent with those reported in other pediatric studies (Riddle et al. 1986).

Because the first 25 subjects were collected by one physician (JE) and the last 20 by another (FXC), we compared the two subgroups by age, height, weight, WISC-R IQ, socioeconomic status, behavioral ratings, and monoamine levels. There were no significant differences between these two subgroups on any of these measures except that MHPG level was higher in the more recently recruited subjects $\left(t_{(37)}=2.65, p=.01\right.$ ). Both subgroups demonstrated the previously reported positive significant correlation between CSF HVA level and teachers' rating of hyperactivity $(r=0.41, n=25, p=$ .04 versus $r=0.50, n=20, p=.02$ ) (Castellanos et al. 1994). Neither CSF 5-HIAA nor MHPG correlated significantly with teachers' or parents' severity ratings on placebo.

Combining the samples, we tested the possible confounding effects of age or height (Nordin et al. 1982; Kruesi et al. 1988b; Blennow et al. 1993; Castellanos et al. 1994) and found that age was negatively and significantly correlated with teachers' ratings of hyperactivity on placebo ( $r=-0.34, n=45$ unless otherwise indicated, $p=.02)$, and conduct ( $r=-0.30, p=.05)$, as well as with CSF HVA $(r=-0.31)$. Height was not significantly correlated with any monoamine metabolite levels or behavioral ratings on placebo except for teachers' hyperactivity $(r=-0.30, p=.05)$. Metabolite levels correlated significantly with each other as expected (HVA and 5-HIAA, $r=0.63, p=.0001$; 5-HIAA and MHPG, $r=$ $0.54, n=39, p=.0004)$, although this did not hold for HVA and MGPH $(r=0.23, n=39, p=.17)$.

\section{Correlations with Measures of Drug Response}

The multiple measures of drug response were also highly intercorrelated, e.g., change scores on MPH for conduct and hyperactivity factors were highly correlated for teachers' and parents' ratings ( $r=0.77, n=45$, and $r=$ $0.71, n=43$, respectively, $p<.0001$ ). Improvement on MPH correlated with improvement on DEX for conduct factor (teachers' $r=0.90, n=45, p<.0001$; parents', $r=$ $0.63, n=42, p<.0001$ ), as well as for hyperactivity factor (teachers', $r=0.82, n=45, p<.0001$; parents', $r=$ $0.73, n=42, p<.0001)$.

As seen in Table 1, CSF HVA correlated significantly and positively with all parents' and teachers' Conners change scores for both stimulants, with Pearson coefficients ranging between $0.32(p<.05)$ and $0.50(p<$ .0001). Not shown are physician C-GAS change scores, which reflected both benefits and side-effects and did not correlate significantly with metabolite levels for either medication. Correlations with 5-HIAA were in the same direction as HVA but were only significant for change on parent hyperactivity factor for both stimulants. Pearson correlations partialling out the effects of age did not appreciably diminish the consistent relationship between CSF HVA and stimulant response.

Improvement on the CPT did not correlate significantly with monoamine metabolite levels for any stimulant.

The behavioral responses to all three stimulants are plotted in Figures 1 and 2 (for teachers' and parents' ratings of hyperactivity, respectively). As is shown in Figure 2, some subjects worsened on medication compared to placebo. We compared the quartile with the "best" response to the quartile with the "worst" response for both MPH and DEX on number and severity of sideeffects, age, IQ, Child Behavior Checklist Internalizing score (Achenbach and Edelbrock 1983), and CPT errors. Only age distinguished these groups, with better responders being significantly younger for $\mathrm{MPH}\left(t_{(18)}=2.74, p=\right.$ $.01)$, but not for $\operatorname{DEX}\left(t_{(16)}=1.37, p=.19\right)$.

\section{Stepwise Multiple Regressions}

Because of the many intercorrelations among the data, stepwise multiple regressions were obtained with CSF monoamines, age, height, and baseline behavioral rat- 
Table 1. Pearson Correlations between Cerebrosponal Fluid Monoamine Metabolites and Measures of Behavorial Response $^{a}$ to Methylphenidate and Dextroamphetamine in 45 Boys with ADHD

\begin{tabular}{|c|c|c|c|c|c|c|c|}
\hline & \multirow[b]{2}{*}{ Age } & \multirow[b]{2}{*}{ Height } & & \multirow[b]{2}{*}{ HVA } & \multirow[b]{2}{*}{ 5-HIAA } & HVA & 5-HIAA \\
\hline & & & & & & $\begin{array}{r}\text { (I } \\
\text { Cor } \\
\text { wi }\end{array}$ & $\begin{array}{l}\text { rtial } \\
\text { lations } \\
\text { age) }\end{array}$ \\
\hline \multicolumn{8}{|l|}{ Methylphenidate } \\
\hline Teacher conduct factor & $\begin{array}{r}-0.31 \\
0.04\end{array}$ & $\begin{array}{c}-0.16 \\
\text { NS }\end{array}$ & $\begin{array}{l}0.72 \\
0.0001\end{array}$ & $\begin{array}{l}\mathbf{0 . 3 5} \\
0.02\end{array}$ & $\begin{array}{r}0.18 \\
\text { NS }\end{array}$ & $\begin{array}{l}0.30 \\
0.06\end{array}$ & $\begin{array}{r}0.18 \\
\text { NS }\end{array}$ \\
\hline Teacher hyperactivity factor & $\begin{array}{r}-0.28 \\
0.06\end{array}$ & $\begin{array}{c}-0.20 \\
\text { NS }\end{array}$ & $\begin{array}{l}\mathbf{0 . 6 2} \\
0.0001\end{array}$ & $\begin{array}{l}0.36 \\
0.01\end{array}$ & $\begin{array}{r}0.16 \\
\text { NS }\end{array}$ & $\begin{array}{l}\mathbf{0 . 3 2} \\
0.04\end{array}$ & $\begin{array}{r}0.19 \\
\text { NS }\end{array}$ \\
\hline Parent conduct factor ${ }^{b}$ & $\begin{array}{r}-0.39 \\
0.01\end{array}$ & $\begin{array}{c}-0.23 \\
\text { NS }\end{array}$ & $\begin{array}{c}0.21 \\
\text { NS }\end{array}$ & $\begin{array}{l}0.36 \\
0.01\end{array}$ & $\begin{array}{r}0.24 \\
\text { NS }\end{array}$ & $\begin{array}{l}\mathbf{0 . 3 1} \\
0.05\end{array}$ & $\begin{array}{l}0.26 \\
0.10\end{array}$ \\
\hline Parent hyperactivity factor & $\begin{array}{r}-0.37 \\
0.01\end{array}$ & $\begin{array}{c}-0.19 \\
\text { NS }\end{array}$ & $\begin{array}{l}0.28 \\
0.06\end{array}$ & $\begin{array}{l}\mathbf{0 . 4 8} \\
0.001\end{array}$ & $\begin{array}{l}\mathbf{0 . 4 4} \\
0.003\end{array}$ & $\begin{array}{l}\mathbf{0 . 4 4} \\
0.004\end{array}$ & $\begin{array}{l}\mathbf{0 . 4 8} \\
0.002\end{array}$ \\
\hline \multicolumn{8}{|l|}{ Dextroamphetamine } \\
\hline Teacher conduct factor & $\begin{array}{r}-0.35 \\
0.02\end{array}$ & $\begin{array}{c}-0.15 \\
\text { NS }\end{array}$ & $\begin{array}{l}\mathbf{0 . 6 0} \\
0.0001\end{array}$ & $\begin{array}{l}\mathbf{0 . 3 9} \\
0.009\end{array}$ & $\begin{array}{r}0.20 \\
\text { NS }\end{array}$ & $\begin{array}{l}0.35 \\
0.02\end{array}$ & $\begin{array}{r}0.23 \\
\text { NS }\end{array}$ \\
\hline Teacher hyperactivity factor & $\begin{array}{c}-0.22 \\
\text { NS }\end{array}$ & $\begin{array}{c}-0.12 \\
\text { NS }\end{array}$ & $\begin{array}{l}\mathbf{0 . 4 7} \\
0.001\end{array}$ & $\begin{array}{l}\mathbf{0 . 3 4} \\
0.02\end{array}$ & $\begin{array}{r}0.18 \\
\text { NS }\end{array}$ & $\begin{array}{l}\mathbf{0 . 3 3} \\
0.03\end{array}$ & $\begin{array}{r}0.21 \\
\text { NS }\end{array}$ \\
\hline Parent conduct factor & $\begin{array}{c}-0.24 \\
\text { NS }\end{array}$ & $\begin{array}{r}-\mathbf{0 . 3 6} \\
0.02\end{array}$ & $\begin{array}{c}0.20 \\
\text { NS }\end{array}$ & $\begin{array}{l}\mathbf{0 . 3 2} \\
0.04\end{array}$ & $\begin{array}{l}0.27 \\
0.08\end{array}$ & $\begin{array}{l}0.26 \\
0.09\end{array}$ & $\begin{array}{l}0.27 \\
0.09\end{array}$ \\
\hline Parent hyperactivity factor & $\begin{array}{c}-0.20 \\
\text { NS }\end{array}$ & $\begin{array}{c}-0.17 \\
\text { NS }\end{array}$ & $\begin{array}{c}0.24 \\
\text { NS }\end{array}$ & $\begin{array}{l}\mathbf{0 . 5 0} \\
0.0006\end{array}$ & $\begin{array}{l}\mathbf{0 . 4 2} \\
0.005\end{array}$ & $\begin{array}{l}\mathbf{0 . 4 8} \\
0.001\end{array}$ & $\begin{array}{l}\mathbf{0 . 4 2} \\
0.007\end{array}$ \\
\hline
\end{tabular}

Boldface entries signify statistical significance.

${ }^{a}$ Conners Rating Scale placebo minus score on best drug week.

${ }^{b} n=43$ for parent ratings due to missing data.

ings as possible predictors of drug response. The only significant predictor of improvement on the teachers' rating of hyperactivity was baseline severity (accounting for $39 \%$ and $22 \%$ of the variance for MPH and DEX, respectively). Baseline ratings of severity accounted for $69 \%$ and $51 \%$ of the variance in the improvement in the teachers' conduct ratings on $\mathrm{MPH}$ and DEX, respectively. In both cases, HVA also significantly and independently predicted improvement, increasing the cumulative $\mathrm{R}^{2}$ to $73 \%$ and $58 \%$, respectively. CSF HVA was the only significant predictor of behavioral response for parents' ratings of hyperactivity $\left(\mathrm{R}^{2}=23 \%\right.$ and $25 \%$ for $\mathrm{MPH}$ and DEX, respectively). Age was the only significant predictor for parents' conduct factor change on $\mathrm{MPH}$ $\left(\mathrm{R}^{2}=15 \%\right)$, although HVA contributed nonsignificantly (cumulative $\mathrm{R}^{2}=21 \%, p=.08$ ). For this same rating on DEX, height significantly predicted response $\left(R^{2}=\right.$ $13 \%$ ) and 5-HIAA also contributed significantly (cumulative $R^{2}=22 \%$ ).

\section{CSF Monoamines and Pemoline}

Behavioral improvement on pemoline also correlated significantly with CSF HVA and 5-HIAA though only for the teachers' ratings of hyperactivity $(r=0.67$ and $r=0.70$, respectively, $n=16, p<.01$ ). Within the subset of 16 subjects who participated in pemoline trials,
CSF HVA and 5-HIAA correlated highly $(r=0.85, p<$ $.0001)$.

\section{DISCUSSION}

We have replicated our prior finding of a significant positive correlation between teachers' hyperactivity rating on placebo and CSF HVA level in an independent sample of 20 additional boys with DSM-III-R-defined ADHD. Utilizing the increased statistical power of the total sample $(n=45)$ and a naturalistic controlled setting, we also confirmed the hypothesis that baseline CSF HVA concentration correlates positively with behavioral improvement after treatment with methylphenidate or dextroamphetamine. Higher CSF HVA predicted greater improvement on parent and teacher ratings, and interestingly, lower HVA was associated with worsening on parent ratings (see Figures 1 and 2). Despite the robust predictive power of ratings of baseline severity, CSF HVA also significantly and independently predicted a modest portion (up to $25 \%$ on some measures) of overall variance associated with change on drug. These results were not confounded by CSF gradient effects, nor by the age of the subjects, nor were they simply due to the phenomenon of regression to the mean, and they were confirmed in the subset of patients 
Figure 1. Pearson correlations between behavioral response (average rating on placebo minus rating on best dose) for Conners Teacher Hyperactivity Factor and CSF HVA on three stimulants: (A) methylphenidate, $r=0.36, n=45, p=.01$; (B) dextroamphetamine, $r=0.34, n=45, p=$ .02; (C) magnesium pemoline, $r=$ $0.67, n=16, p<.01$.
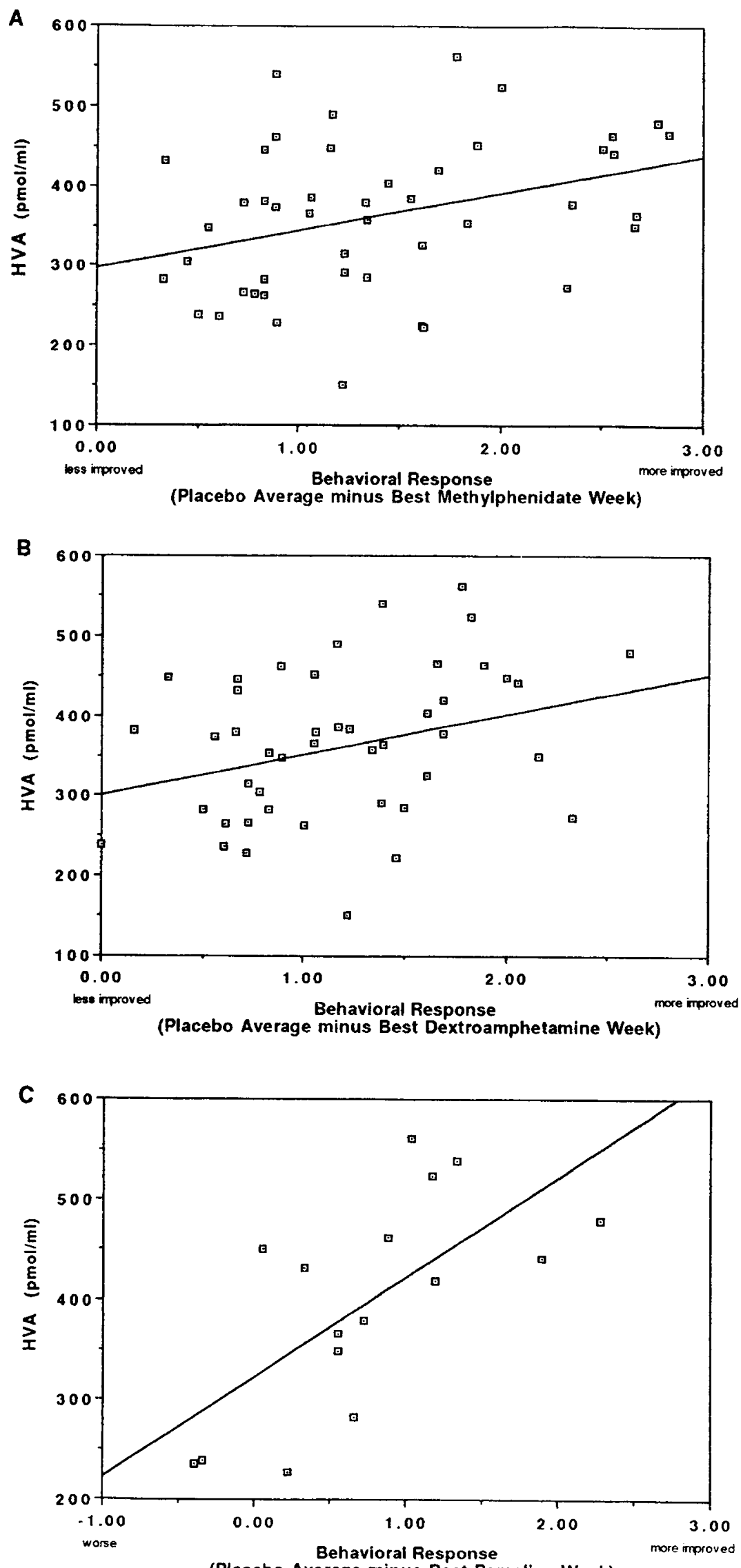

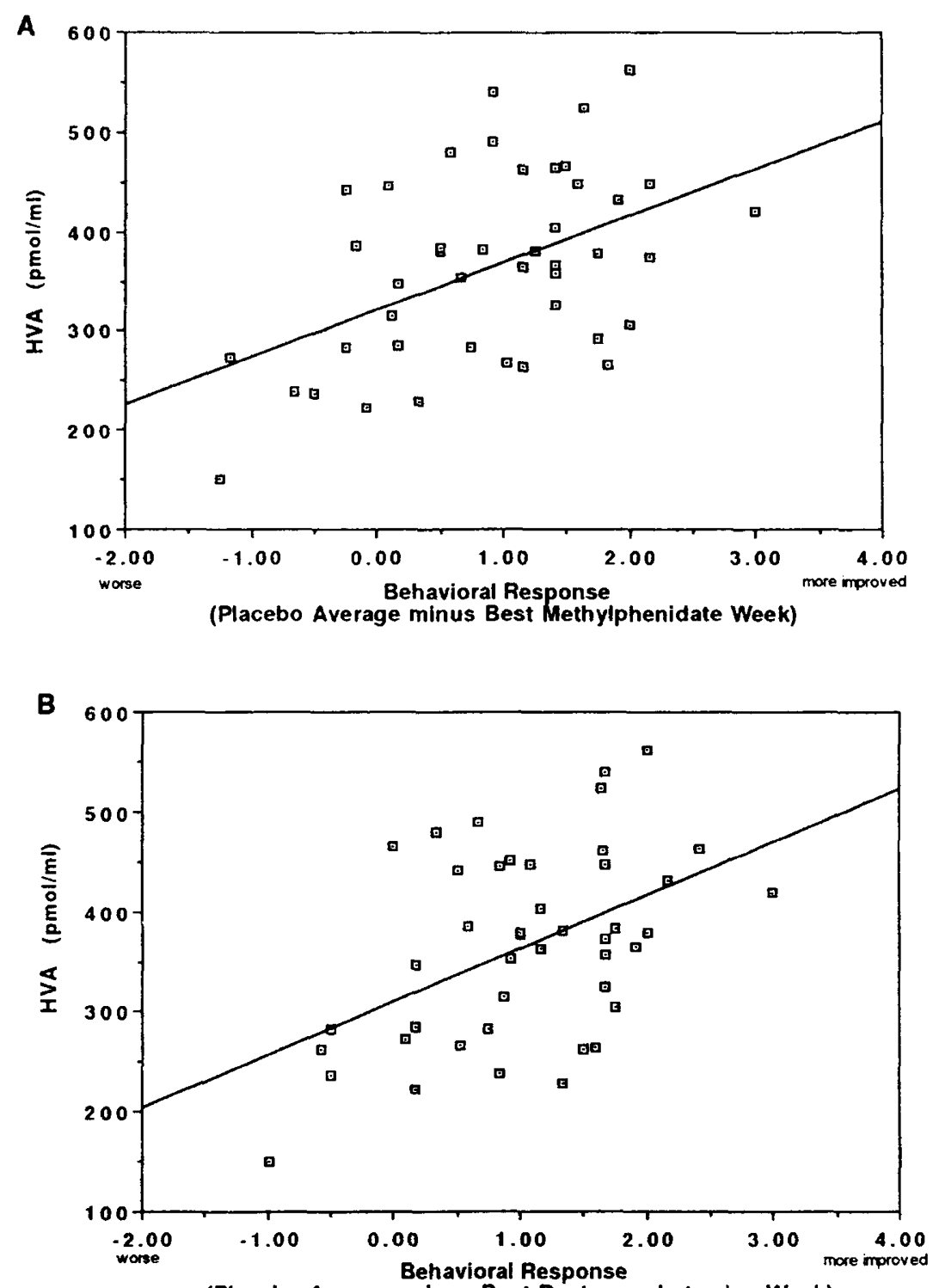

(Placebo Average minus Best Dextroamphetamine Week)

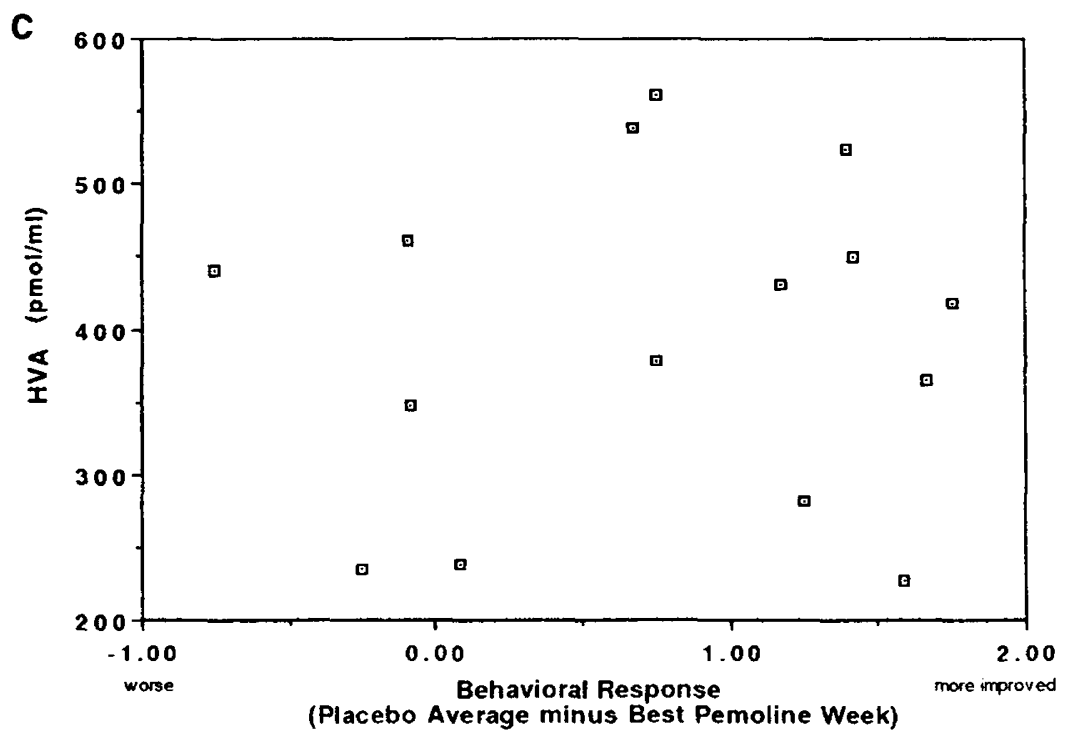

Figure 2. Pearson correlations between behavioral response (average rating on placebo minus rating on best dose) for Conners Parents' Hyperactivity Factor and CSF HVA on three stimulants: (A) methylphenidate, $r=0.48, n=45, p=.001$; (B) dextroamphetamine, $r=0.50, n=45$, $p=.0006,(\mathrm{C})$ magnesium pemoline, $r=0.08, n=16$, NS. 
who participated in an extension of this study with the "atypical" stimulant pemoline.

There are several limitations of this study. Most of our subjects were not drug naive, and although all were medication-free for at least 4 weeks, that washout period may not have been long enough to "reset the system to neutral" (Zametkin et al. 1985; Ziegler et al. 1980). However, CSF HVA did not differ significantly for the drugnaive subjects $(n=9)$ compared to those with a prior history of stimulant exposure. In addition, we did not have a control or comparison group, thus we cannot evaluate whether the "high HVA" subjects who were among the best responders are outside the normal range. Previous reports in ADHD have also been unsatisfactory in the number of normal controls (Shetty and Chase 1976) or their nature (Reimherr et al. 1984). Difficulty obtaining appropriate controls is inherent to pediatric CSF research and is not likely to change (Arnold et al. 1995). Nonetheless, the three prior CSF studies (Shetty and Chase 1976; Shaywitz et al. 1977; Reimherr et al. 1984) do not support consistent CSF HVA abnormalities in ADHD. This same situation obtains in schizophrenia studies, in which patients and normals do not vary significantly in net CSF or plasma levels of HVA, although significant differences have been found in parameters thought to reflect abnormal regulation of monoaminergic systems (Stern et al. 1993; Hsiao et al. 1993; Kahn et al. 1993; Potter and Manji 1993).

Our pemoline trial was small, combines blind and nonblind ratings, and drug order was not controlled; thus, we can not compare efficacy of the stimulants. It is worth noting, however, that pemoline was the preferred medication for only one of the 16 patients who received all three stimulants, in keeping with general clinical experience (Wiener 1995).

We did not find significant correlations between MHPG and behavioral ratings of severity on placebo or of improvement on medication. This was not unexpected, as it has been estimated that more than $50 \%$ of CSF MHPG derives from spinal cord (Garelis et al. 1974; Sjöström et al. 1975). However, the decreased reliability of our MHPG levels, the presence of several outliers only for MHPG, the finding of significantly lower MHPG levels in those samples that had been stored longest, and the well established efficacy in ADHD of medications that are primarily noradrenergic (Donnelly et al. 1986; Biederman et al. 1989; Hunt et al. 1986; Arnsten and Contant 1992; Hunt et al. 1995; Zametkin and Rapoport 1987; Mefford and Potter 1989; McCracken 1991) all support caution in interpreting this negative result. On the other hand, the relative specificity of our results for HVA argues that they are not due to nonspecific alterations in the anion-transport pump at the brain-CSF-venous interfaces (Westerink and Kikkert 1986; Amin et al. 1992).

Our ability to independently replicate our prior unexpected finding (Castellanos et al. 1994), even with a relatively small group of 20 new subjects, lends credence to our result of a positive significant correlation between ratings of hyperactivity on placebo and CSF HVA, which is further buttressed by the emergence of CSF HVA as an independent, although modest, significant predictor of stimulant response.

The most serious limitation on interpretation of our results is inherent to the study of CSF monoamines (Kopin 1985; Commissiong 1985). Simply put, if we were able to confirm that stimulants decrease CSF HVA in relation to their behavioral effects in ADHD (Shetty and Chase 1976; Cohen et al. 1980), we would still be unable to determine if this was because of (1) presynaptic compensation for defective postsynaptic signal transduction, (2) overactive intraneuronal metabolism unrelated to synaptically released dopamine, or (3) autoreceptormediated downregulation of excessive dopaminergic neurotransmission.

The first alternative has historically received the most support, deriving from putative animal models based on selective lesions of midbrain dopaminergic neurons (Shaywitz et al. 1978; Shenker 1992; Roeltgen and Schneider 1991; Kostrzewa et al. 1994), a prior CSF study in children diagnosed with minimal brain dysfunction (Shaywitz et al. 1977), and a voluminous literature indicating that acute applications of stimulants increase dopamine and its metabolites in vitro (reviewed in Creese 1983). However, models that support the "low central dopamine" hypothesis have their own weaknesses: they generally rely on substantial lesions of the dopaminergic system, which would presumably be detectable in central or peripheral measures of catecholamine activity, and they have usually been validated on the basis of stimulant-mediated decreases in motoric hyperactivity. In fact, stimulant effects are not specific (or "paradoxical") to individuals with ADHD (Rapoport et al. 1978), and they do not simply decrease motor activity. Rather, their modulation of motoric activity through appropriate increases and decreases (Porrino et al. 1983) appears to be paralleled by excitatory and inhibitory effects on striatal neurons in awake, behaving rats (Pierce and Rebec 1995). Dissociation of stimulant effects is also suggested by Volkow et al.'s report that although the time course of euphoria in normal adult volunteers after intravenous cocaine coincides with clearance of labeled cocaine from striatum, euphoria after intravenous MPH resolves as quickly, even though MPH clearance is over four times slower (Volkow et al. 1995).

The second possibility is being addressed indirectly with positron emission tomograhy (PET) studies with labeled ${ }^{18} \mathrm{~F}$-dopa (personal communication, Dr. A. Zametkin, April 1995) aimed at determining if ADHD individuals have increased or decreased numbers of presynaptic striatal dopamine terminals. 
The third conjecture, that stimulant efficacy in childhood hyperactivity is linked to autoreceptor-mediated modulation of striatal dopaminergic system has been proposed by Levy (1991), and is indirectly supported by a number of observations. In a recent extensive review, Amin et al. (1992) concluded that despite numerous methodologic difficulties, measurement of HVA remains "the most direct method currently available in living humans to assess the changing activity of central dopaminergic neurons." They also determined that "CSF HVA appears to originate ... mainly from a portion of the striatum adjacent to the lateral ventricular walls. CSF HVA concentrations probably reflect only major changes in the striatal dopaminergic neuronal activity" (Amin et al. 1992). Although the three commonly used stimulants vary in their monoaminergic profiles, all are reported to increase extracellular dopamine concentrations, albeit by varying mechanisms (Kuczenski and Segal 1975; Rebec and Segal 1978; Kuczenski and Segal 1992; Fung and Uretsky 1982; Lloyd and Stone 1983; Braestrup and Scheel-Kruger 1976; Duteil et al. 1987; Schweri et al. 1985; Patrick et al. 1987; Schweri 1994; Molina and Orsingher 1981; Tagliamonte and Tagliamonte 1971). Although a comparison is not appropriate given differences in experimental conditions and sample sizes, it is interesting that the prediction of drug response appeared particularly robust for pemoline (accounting for $48 \%$ of the variance on our teachers' ratings), which has been claimed to be the most "purely dopaminergic" (Everett 1981).

Although most preclinical studies use higher doses, a few have found that clinically relevant doses of stimulants have inhibitory effects on striatal (Rebec and Segal 1978) and nigrostriatal (Bunney et al. 1973) neuronal activity. In drug-naive behaving rats, striatal dopamine and metabolite levels obtained by microdialysis correlated modestly but significantly ( $r=0.45$ for HVA) with motoric activity (Paulson and Robinson 1994). Behaviorally, a very low dose of methylphenidate $(0.1 \mathrm{mg} / \mathrm{kg})$ was found to significantly decrease hyperactivity in ADHD children in a placebo-controlled study (Solanto 1986). This finding was interpreted as evidence for autoreceptor-mediated efficacy because of the greater potency of dopaminergic agonists on presynaptic autoreceptors (Drukarch and Stoof 1990; Meador-Woodruff et al. 1994).

Neuropsychological evaluations have consistently found that ADHD children have a "neurodevelopmental lag" of approximately 2 to 4 years, particularly in putative tests of frontal function (Kinsbourne 1973; Chelune et al. 1986; Amin et al. 1993). Although CSF monoamines from truly normal children have never been examined, studies in various pediatric contrast groups demonstrate that CSF HVA decreases substantially across the pediatric age range (Leckman et al. 1980; Hedner et al. 1986; Kruesi et al. 1988b). We also found a significant decrease in CSF HVA even across our fairly narrow age range. There is an interesting parallel between the normal decrease in CSF HVA with age, and the decreases in motoric restlessness and fidgetiness noted in both "normal" and ADHD children as they approach puberty (Hart et al. 1994). However, although the hypothesis of higher dopaminergic activity driving motoric restlessness is attractive, the possibility exists that the causal relationship is reversed. For example, in depressed patients as well as in rats, increased physical activity for only several hours resulted in increased levels of CSF HVA and 5-HIAA (Post et al. 1973; Chaouloff et al. 1986) —although this is unlikely as our patients were at bed rest for at least 9 hours before LP.

The questions raised by our data are not answered by prior CSF studies in ADHD. The only other systematic investigation of CSF monoamine metabolites in relation to stimulant response compared baseline CSF HVA from 15 adults with attention deficit disorder, residual type, who were then treated with methylphenidate (Reimherr et al. 1984). No quantitative relationships between CSF HVA and drug response were found, except by using a post hoc separation of four "nonresponders" for whom CSF HVA was higher. Their cautions about interpretation of this result appear warranted. The pioneering study by Shaywitz et al. (1977) did not examine stimulant response, and only found differences in the ratio of CSF HVA to probenecid, which is also difficult to interpret (Cowdry et al. 1983). Unfortunately, as noted previously, even further study of CSF and drug response is unlikely to distinguish between these and other possible hypotheses.

Although we are not currently pursuing further CSF studies, we note that subjects with low HVA tended to respond less well to stimulants, with some even deteriorating. This was not due to a higher incidence of stimulant side-effects in low HVA subjects. Only long-term follow-up, now in progress, will determine if low values of CSF monoamines, particularly 5-HIAA, predict worse outcome as has been found before with a group of conduct-disordered children (Kruesi et al. 1992).

In summary, behavioral improvement in hyperactivity was predicted by baseline CSF HVA levels, controlling for confounding factors such as age, height, or baseline behavioral symptom severity. The three stimulants may vary in the extent to which they affect other monoamines, but all three produce an initial increase in extracellular dopamine. Our results are consistent with, but do not prove, the notion that stimulants decrease hyperactivity in part by decreasing dopamine turnover, most probably in the striatum, by activation of inhibitory presynaptic autoreceptors. This is the first finding of a significant direct relationship between baseline CSF metabolite levels and subsequent behavioral response to medications. This may be because the behavioral effects of the stimulants are rapid in contrast to other 
psychotropic agents, with such correlative data a valid reflection of stimulant clinical effects. Further progress, however, is likely to come from functional imaging and primate studies that can better test these hypotheses.

\section{ACKNOWLEDGMENTS}

The authors thank Jerry Oliver for mass spectroscopy determinations; the NIMH Outpatient Clinic Nursing Staff, Kathleen Berzin, R.N., Eddie Frazier, R.N., and Sue Squires, R.N. and their predecessors for exemplary clinical care; our dedicated school teachers, Phyllis Siegrist, Ann Davidson, Deborah Thompson, and Pat Welch for their careful observations; the NIH Recreation Department Staff and Recreation Therapists Debbie Davis Cohen and Robin Greenfield; and most of all, the parents and children who participated in this study.

\section{REFERENCES}

Achenbach T, Edelbrock C (1983): Manual for the Child Behavior Checklist and Revised Child Behavior Profile. University of Vermont, Burlington, VT, Department of Psychiatry

Amin F, Davidson M, David KL (1992): Homovanillic acid in clinical research: A review of methodology. Schizophr Bull 18:123-148

Amin K, Douglas VT, Mendelson MJ, Dufresne J (1993): Separable/integral classification by hyperactive and normal children. Dev Psychopathol 5:415-431

Anderson GM, Riddle MA, Hoder EL, Feibel FC, Shaywitz BA, Cohen DJ (1988): The ontogeny of 3,4-dihydroxyphenylacetic acid in human cerebrospinal fluid. J Neurol Neurosurg Psychiatry 51:1,100-1,102

Arnold LE, Stoff DM, Cook E, Jr., Cohen DJ, Kruesi M, Wright C, Hattab J, Graham P, Zametkin A, Castellanos FX, McMahon W, Leckman JF (1995): Ethical issues in biological mental health research with children \& adolescents. J. Am Acad Child Adolesc Psychiatry 34:929939

Arnsten AF, Contant TA (1992): $\alpha_{2}$ adrenergic agonists decrease distractibility in aged monkeys performing the delayed response task. Psychopharmacology (Berl) 108: 159-169

Biederman J, Baldessarini RJ, Wright V, Knee D, Harmatz JS (1989): A double-blind, placebo-controlled study of desipramine in the treatment of ADD: I. Efficacy. J Am Acad Child Adolesc Psychiatry 28:777-784

Blennow K, Wallin A, Gottfries CG, Mansson JE, Svennerholm L (1993): Concentration gradients for monoamine metabolites in lumbar cerebrospinal fluid. J Neural Transm Park Dis Dement Sect 5:5-15

Bonadio WA, Smith DS, Metrou M, Dewitz B (1988): Estimating lumbar-puncture depth in children [letter]. N Engl J Med 319:952-953

Borcherding BG, Keysor CS, Cooper TB, Rapoport JL (1989): Differential effects of methylphenidate and dextroamphetamine on the motor activity level of hyperactive children. Neuropsychopharmacology 2:255-263
Braestrup C, Scheel-Kruger J (1976): Methylphenidate-like effects of the new antidepressant drug nomifensine (HOE 984). Eur J Pharmacol 38:305-312

Bunney BS, Walters JR, Roth RH, Aghajanian GK (1973): Dopaminergic neurons: Effects of antipsychotic drugs and amphetamines on single cell activity. J Pharmacol Exp Ther 185:560-571

Castellanos FX, Elia J, Kruesi MJ, Gulotta CS, Mefford IN, Potter WZ, Ritchie GF, Rapoport JL (1994): Cerebrospinal fluid monoamine metabolites in boys with attentiondeficit hyperactivity disorder. Psychiatry Res 52:305-316

Chaouloff F, Laude D, Guezennec Y, Elghozi JL (1986): Motor activity increases tryptophan, 5-hydroxyindoleacetic acid, and homovanillic acid in ventricular cerebrospinal fluid of the conscious rat. J Neurochem 46:1,313-1,316

Chelune GJ, Ferguson W, Koon R, Dickey TO (1986): Frontal lobe disinhibition in attention deficit disorder. Child Psychiatry Hum Dev 16:221-234

Cohen DJ, Shaywitz BA, Young JG, Bowers MB, Jr (1980): Cerebrospinal fluid monoamine metabolites in neuropsychiatric disorders of childhood. In Wood JH (ed), Neurobiology of Cerebrospinal Fluid. New York, Plenum, pp 665-683

Commissiong JW (1985): Monoamine metabolites: Their relationship and lack of relationship to monoaminergic neuronal activity. Biochem Pharmacol 34:1,127-1,131

Cowdry RW, Ebert MH, van Kammen DP, Post RM, Goodwin FK (1983): Cerebrospinal fluid probenecid studies: A reinterpretation. Biol Psychiatry 18:1,287-1,299

Creese I (ed), (1983): Stimulants: Neurochemical, Behavioral, and Clinical Perspectives. New York, Raven

Donnelly M, Zametkin AJ, Rapoport JL, Ismond DR, Weingartner H, Lane E, Oliver J, Linnoila M, Potter WZ (1986): Treatment of childhood hyperactivity with desipramine: Plasma drug concentration, cardiovascular effects, plasma and urinary catecholamine levels, and clinical response. Clin Pharmacol Ther 39:72-81

Donnelly M, Rapoport JL, Potter WZ, Oliver J, Keysor CS, Murphy DL (1989): Fenfluramine and dextroamphetamine treatment of childhood hyperactivity. Arch Gen Psychiatry 46:205-212

Drukarch B, Stoof JC (1990): D-2 dopamine autoreceptor selective drugs: Do they really exist? Life Sci, 47:361-376

Duteil J, de Sereville JE, Multon MF, Pessonnier J, Rambert FA (1987): [Stereotyped movements and substantia nigra-corpus striatum dopaminergic function in the rat: Action of methylphenidate after inhibition of monoamine oxidase]. Ann Pharm Fr 45:25-34

Elia J, Borcherding BG, Potter WZ, Mefford IN, Rapoport JL, Keysor CS (1990): Stimulant drug treatment of hyperactivity: Biochemical correlates. Clin Pharmacol Ther 48: 57-66

Elia J, Borcherding BG, Rapoport JL, Keysor CS (1991): Methylphenidate and dextroamphetamine treatments of hyperactivity: Are there true nonresponders? Psychiatry Res 36:141-155

Everett GM (1981): Pemoline: A specific long-acting dopaminomimetic drug. In Gessa GL, Corsini GU (eds), Apomorphine and Other Dopaminomimetics, vol 1. Basic Pharmacology. New York, Raven, pp 261-263 
Fung YK, Uretsky NJ (1982): The differential effects of amphetamine and methylphenidate on the biosynthesis of $[3 \mathrm{H}]$ dopa from [3H]tyrosine in mouse striata in vivo. J Pharm Pharmacol 34:531-532

Garelis E, Young SN, Lal S, Sourkes TL (1974): Monoamine metabolites in lumbar CSF. The question of their origin in relation to clinical studies. Brain Res 79:1-8

Goyette CH, Conners CK, Ulrich RF (1978): Normative data on revised Conners Parent and Teacher Rating Scales. J Abnorm Child Psychol 6:221-236

Gualtieri CT, Hicks RE (1985): Neuropharmacology of methylphenidate and a neural substrate for childhood hyperactivity. Psychiatr Clin North Am 8:875-892

Guy W (1976): Subject's treatment emergent symptom scale. In Guy W (ed), Assessment Manual for Psychopharmacology. Washington, DC, U.S. Government Printing Office, pp 347-350

Hart EL, Lahey BB, Loeber R, Appelgate B, Frick PJ (1995): Developmental change in attention-deficit/hyperactive disorder in boys: a four year longitudinal study. J Abnorm Child Psychol (in press)

Hedner J, Lundell KH, Breese GR, Mueller RA, Hedner T (1986): Developmental variations in CSF monoamine metabolites during childhood. Biol Neonate 49:190-197

Herjanic B, Campbell W (1977): Differentiating psychiatrically disturbed children on the basis of a structured interview. J Abnorm Child Psychol 5:127-134

Hsiao JK, Colison J, Bartko JJ, Doran AR, Konicki PE, Potter WZ, Pickar D (1993): Monoamine neurotransmitter interactions in drug-free and neuroleptic-treated schizophrenics. Arch Gen Psychiatry 50:606-614

Hunt RD, Minderaa RB, Cohen DJ (1986): The therapeutic effect of clonidine in attention deficit disorder with hyperactivity: A comparison with placebo and methylphenidate. Psychopharmacol Bull 22:229-236

Hunt RD, Arnsten AF, Asbell MD (1995): An open trial of guanfacine in the treatment of attention-deficit hyperactivity disorder. J Am Acad Child Adolesc Psychiatry 34: $50-54$

Kahn RS, Davidson M, Knott P, Stern RG, Apter S, Davis KL (1993): Effect of neuroleptic medication on cerebrospinal fluid monomine metabolite concentrations in schizophrenia. Arch Gen Psychiatry 50:599-605

Karoum F (1983): Mass fragmentography in the analysis of biogenic amines. In Nagutsu T, Nagatsu I, Parvez H (eds), Methods in Biogenic Amine Research. New York, Elsevier, pp 237-255

Kinsbourne M (1973): Minimal brain dysfunction as a neurodevelopmental lag. Ann NY Acad Sci 205:268-273

Kopin IJ (1985): Catecholamine metabolism: Basic aspects and clinical significance. Pharmacol Rev 37:333-364

Kornetsky C (1970): Psychoactive drugs in the immature organism. Psychopharmacologia 17:105-136

Kostrzewa RM, Brus R, Kalbfleisch JH, Perry KW, Fuller RW (1994): Proposed animal model of attention deficit hyperactivity disorder. Brain Res Bull 34:161-167

Kruesi MJP, Swedo SE, Coffey ML, Hamburger SD, Leonard H,Rapoport JL (1988a): Objective and subjective side effects of research lumbar punctures in children and adolescents. Psychiatry Res 25:59-63
Kruesi MJP, Swedo SE, Hamburger SD, Potter WZ, Rapoport JL (1988b): Concentration gradient of CSF monoamine metabolites in children and adolescents. Biol Psychiatry 24:507-514

Kruesi MJP, Hibbs ED, Zahn TP, Keysor CS, Hamburger SD, Bartko JJ, Rapoport JL (1992): A 2-year prospective follow-up study of children and adolescents with disruptive behavior disorders. Arch Gen Psychiatry 49:429-435

Kuczenski R, Segal DS (1975): Differential effects of D- and L-amphetamine and methylphenidate on rat striatal dopamine biosynthesis. Eur J Pharmacol 30:244-251

Kuczenski R, Segal DS (1992): Regional norepinephrine response to amphetamine using dialysis: Comparison with caudate dopamine. Synapse 11:164-169

Leckman JF, Cohen DJ, Shaywitz BA, Caparulo BK, Heninger GR, Bowers MB, Jr. (1980): CSF monoamine metabolites in child and adult psychiatric patients. A developmental perspective. Arch Gen Psychiatry 37: 677-681

Levy F (1991): The dopamine theory of attention deficit hyperactivity disorder (ADHD). Aus NZJ Psychiatry 25: 277-283

Lloyd HGE, Stone TW (1983): The effects of some CNS stimulants on dopamine and 5HT release from rat striatal slices. Br J Pharmacol 78:\$93

McCracken JT (1991): A two-part model of stimulant action on attention-deficit hyperactivity disorder in children. J Neuropsychiatry 3:201-209

Meador-Woodruff JH, Damask SP, Watson SJ, Jr. (1994): Differential expression of autoreceptors in the ascending dopamine systems of the human brain. PNAS 91:8,2978,301

Mefford, IN, Potter WZ (1989): A neuroanatomic and biochemical basis for attention deficit disorder with hyperactivity in children: A defect in tonic adrenaline mediated inhibition of locus coeruleus stimulation. Med Hypotheses 29:33-42

Molina VA, Orsingher OA (1981): Effects of Mg-pemoline on the central catecholaminergic system. Arch Int Pharmacodyn Ther 251:66-79

Nordin C, Siwers B, Bertilsson L (1982): Site of lumbar puncture influences levels of monoamine metabolites. Arch Gen Psychiatry 39:1,445

Patrick KS, Caldwell RW, Ferris RM, Breese GR (1987): Pharmacology of the enantiomers of threo-methylphenidate. J Pharmacol Exp Ther 241:152-158

Paulson PE, Robinson TE (1994): Relationship between circadian changes in spontaneous motor activity and dorsal versus ventral striatal dopamine neurotransmission assessed with on-line microdialysis. Behav Neurosci 108: 624-635

Pierce RC, Rebec GV (1995): Iontophoresis in the neostriatum of awake, unrestrained rats: differential effects of dopamine, glutamate, and ascorbate on motor- and nonmotor-related neurons. Neuroscience 67:313-324

Porrino LJ, Rapoport JL, Behar D, Ismond DR, Bunney WE, Jr. (1983): A naturalistic assessment of the motor activity of hyperactive boys. II. Stimulant drug effects. Arch Gen Psychiatry 40:688-693

Post RM, Kotin J, Goodwin FK, Gordon EK (1973): Psycho- 
motor activity and cerebrospinal fluid amine metabolites in affective illness. Am J Psychiatry 130:67-72

Potter WZ, Manji HK (1993): Are monoamine metabolites in cerebrospinal fluid worth measuring? Arch Gen Psychiatry 50:653-656

Rapoport JL, Buchsbaum MS, Zahn TP, Weingartner H, Ludlow C, Mikkelsen EJ (1978): Dextroamphetamine: Cognitive and behavioral effects in normal prepubertal boys. Science 199:560-563

Rapport MD, DuPaul GJ, Stoner G, Jones TJ (1986): Comparing classroom and clinic measures of attention deficit disorder: Differential, idiosyncratic, and dose-response effects of methylphenidate. J Consult Clin Psychol 54: 334-341

Rebec GV, Segal DS (1978): Dose-dependent biphasic alterations in the spontaneous activity of neurons in the rat neostriatum produced by D-amphetamine and methylphenidate. Brain Res 150:353-366

Reimherr FW, Wender PH, Ebert MH, Wood DR (1984): Cerebrospinal fluid homovanillic acid and 5-hydroxyindoleacetic acid in adults with attention deficit disorder, residual type. Psychiatry Res 11:71-78

Riddle MA, Anderson GM, McIntosh S, Harcherik DF, Shaywitz BA, Cohen DJ (1986): Cerebrospinal fluid monoamine precursor and metabolite levels in children treated for leukemia: Age and sex effects and individual variability. Biol Psychiatry 21:69-83

Roeltgen DP, Schneider JS (1991): Chronic low-dose MPTP in nonhuman primates: A possible model for attention deficit disorder. J Ch Neurol 6:S82-S89

Rosvold HE, Mirsky AF, Sarason I, Bransome ED, Beck LH (1956): A continuous performance test of brain damage. J Consul Psychol 20:343-350

SAS Institute, I (1989): SAS Language and Procedures: Usage, version 6, ed 1. Cary, NC, SAS Institute

SAS Institute, I (1990): SAS Procedures Guide, Version 6, ed 3. Cary, NC, SAS Institute

Schweri MM, Skolnick P, Rafferty MF, Rice KC, Janowsky AJ, Paul SM (1985): [3H]Threo-(+/-)-methylphenidate binding to 3,4-dihydroxyphenylethylamine uptake sites in corpus striatum: Correlation with the stimulant properties of ritalinic acid esters. J. Neurochem 45:1,062-1,070

Schweri MM (1994): Mercuric chloride and p-chloromercuriphenylsulfonate exert a biphasic effect on the binding of the stimulant $[3 \mathrm{H}]$ methylphenidate to the dopamine transporter. Synapse 16:188-194

Shaffer D, Gould MS, Brasie J, Ambrosini P, Fisher P, Bird H, Aluwahlia S (1983): A children's global assessment scale (CGAS). Arch Gen Psychiatry 40:1,228-1,231

Shaywitz BA, Cohen DJ, Bowers MB (1977): CSF amine metabolites in children with minimal brain dysfunction: Evidence for alteration of brain dopamine-a preliminary report. J Pediatr 90:67-71

Shaywitz BA, Klopper JH, Gordon JW (1978): Methylphenidate in 6-hydroxydopamine-treated developing rat pups. Effects on activity and maze performance. Arch Neurol 35:463-469

Shaywitz BA, Cohen DJ, Leckman JF, Young JG, Bowers MB, Jr. (1980): Ontogeny of dopamine and serotonin metabo- lites in the cerebrospinal fluid of children with neurologic disorders. Dev Med Child Neurol 22:748-754

Shaywitz SE, Cohen DJ, Shaywitz BA (1978): The biochemical basis of minimal brain dysfunction. J Pediatr 92: 179-187

Shekim WO, Sinclair E, Glaser R, Horwitz E, Javaid J, Bylund DB (1987): Norepinephrine and dopamine metabolites and educational variables in boys with attention deficit disorder and hyperactivity. J Ch Neurol 2:50-56

Shenker A (1992): The mechanism of action of drugs used to treat attention-deficit hyperactivity disorder: Focus on catecholamine receptor pharmacology. Adv Pediatr 39: 337-382

Shetty T, Chase TN (1976): Central monoamines and hyperkinesis of childhood. Neurology 26:1,000-1,006

Sjöström R, Ekstedt J, Anggard E (1975): Concentration gradients of monoamine metabolites in human cerebrospinal fluid. J Neurol Neurosurg Psychiatry 38:666-668

Solanto MV (1986): Behavioral effects of low-dose methylphenidate in childhood attention deficit disorder: Implications for a mechanism of stimulant drug action. J Am Acad Child Psychiatry 25:96-101

Stern RG, Kahn RS, Davidson M (1993): Predictors of response to neuroleptic treatment in shizophrenia. Psychiatr Clin North Am 16:313-338

Tagliamonte A, Tagliamonte P (1971): Stimulation of brain dopamine turnover by magnesium pemoline (MgP). Fed Proc 30:223

Volkow ND, Ding YS, Fowler JS, Wang GJ, Logan J, Gatley JS, Dewey S, Ashby C, Lieberman J, Hitzemann R, Wolf AP (1995): Is methylphenidate like cocaine? Studies on their pharmacokinetics and distribution in human brain. Arch Gen Psychiatry 52:456-463

Wechsler, D (1974): Manual for the Wechsler Intelligence Scale for Children-Revised. New York, The Psychological Corporation

Wender PH (1973): Some speculations concerning a possible biochemical basis of minimal brain dysfunction. Ann NY Acad Sci 205:81-28

Werry JS, Sprague RL, Cohen MN (1975): Conners' Teacher Rating Scale for use in drug studies with children-an empirical study. J Abnorm Child Psychol 3:217-229

Westerink BH, Kikkert RJ (1986): Effect of various centrally acting drugs on the efflux of dopamine metabolites from the rat brain. J Neurochem 46:1,145-1,152

Wiener JN (ed), (1995): Diagnosis and Psychopharmacology of Child and Adolescent Disorders, ed 2. New York, John Wiley \& Sons, Inc.

Woodcock RW, Johnson BB (1977): Woodcock-Johnson Psychoeducational Battery. Allen, TX, DLM Teaching Resources

Zametkin A, Rapoport JL, Murphy DL, Linnoila M, Karoum F, Potter WZ, Ismond D (1985): Treatment of hyperactive children with monoamine oxidase inhibitors. II. Plasma and urinary monoamine findings after treatment. Arch Gen Psychiatry 42:969-973

Zametkin AJ, Karoum F, Linnoila M, Rapoport JL, Brown GL, Chuang LW, Wyatt RJ (1985a): Stimulants, urinary catecholamines, and indoleamines in hyperactivity. Arch Gen Psychiatry 42:251-255 
Zametkin AJ, Hamburger SD (1988): The effect of methylphenidate on urinary catecholamine excretion in hyperactivity: A partial replication. Biol Psychiatry 23:350-356

Zametkin AJ, Rapoport JL (1987): Noradrenergic hypothesis of attention deficit disorder with hyperactivity: A critical review. In Meltzer HY (ed), Psychopharmacology:
The Third Generation of Progress. New York, Raven, pp 837-842

Ziegler MG, Lake CR, Wood JH, Ebert MH (1980): Norepinephrine in cerebrospinal fluid. In Wood JH (ed), Neurobiology of Cerebrospinal Fluid. New York, Plenum, pp 141-151 